\title{
RECONHECIMENTO, CONFLITO E FORMAÇÃO NA TEORIA CRÍTICA DE AXEL HONNETH
}

\author{
Angelo Vitório Cenci*
}

\begin{abstract}
RESUMO
Honneth explora, em sua teoria crítica, um tipo de conflito impulsionado por experiências de desrespeito que afetam a identidade pessoal ou coletiva. Ao retomar ao jovem Hegel, situa o conflito no núcleo central de sua teoria social crítica, concebendo-o como distúrbio ou lesão nas relações sociais de reconhecimento. Além de atribuir ao conflito o papel de motor da interação social, confere-lhe a função de elemento formador da identidade humana na medida em que permite ao sujeito desenvolver positivamente uma autorrelação prática por meio de diferentes esferas do reconhecimento. O presente artigo toma como ponto de partida as teses centrais da teoria do reconhecimento honnethiana e a apresentação das diferentes dimensões do conflito presentes nela para mostrar como é possível encontrar, em tal teoria, um importante vínculo entre conflito e formação, sobretudo, mediante os conceitos de socialização e autorrealização.
\end{abstract}

Palavras-chave: Reconhecimento. Conflito. Formação.

\begin{abstract}
In his critical theory, Honneth explores a kind of conflict driven by experiences of disrespect that affect personal or collective identity. When addressing the young Hegel, he places the conflict at the core of his critical social theory, conceiving it as a disorder or lesion in social relations of recognition. Besides ascribing the conflict its role as power engine of social interaction, he assigns it with the role of formation element of human identity as long as it allows the subject to positively develop
\end{abstract}

\footnotetext{
* Doutor e pós-doutor pela Universidade de Campinas (UNICAMP). Professor e pesquisador do Curso de Filosofia e do Programa de Pós-Graduação em Educação da Universidade de Passo Fundo/RS. E-mail: angelo@upf.br
} 
some practical self-relation through different spheres of recognition. This paper takes as its starting point the central theses of Honneth's theory of recognition and the presentation of the different dimensions of the conflict inherent to it so as to show how it is possible to find, in such theory, an important bond between conflict and formation, above all, through the concepts of socialization and self-realization.

Keywords: Recognition. Conflict. Formation.

\section{Introdução}

Honneth, na esteira de Hegel, opera um deslocamento em relação à concepção de conflito como luta por poder ou por autoconservação predominante na filosofia social moderna, detendo-se num tipo específico de conflito, qualseja,aqueleoriginadoporexperiênciasdedesrespeitoqueafetam a identidade pessoal ou coletiva. O autor toma como fio condutor a ideia de que os indivíduos somente podem constituir as suas identidades se puderem ser reconhecidos intersubjetivamente. Nesse sentido, retoma o jovem Hegel para quem o modelo de luta social pode ser compreendido como processo prático de conflito entre os homens atribuído a impulsos morais, de modo a entendê-lo como distúrbio e lesão nas relações sociais de reconhecimento.

O jovem Hegel (1992) postulara que a formação do espírito humano dá-se de acordo com um processo que leva gradualmente a uma ampliação das condições prévias do reconhecimento recíproco. Nessa posição reside uma noção de progresso moral que se desenvolve mediante três padrões de reconhecimento com uma complexidade crescente e entre os quais se coloca, a cada vez, uma luta intersubjetiva entre os indivíduos por meio da qual reivindicam a formação de suas identidades. Ao considerar os conflitos sociais como possuidores de um potencial de aprendizado prático-moral, o jovem Hegel imprime uma nova orientação ao modelo de luta social introduzido na filosofia social por Maquiavel e Hobbes. Honneth, por seu turno, recorre a essa herança e a sua intenção é retomar o modelo original de luta por reconhecimento na perspectiva de uma teoria social de teor normativo, vinculandolhe um conceito de luta que parta de sentimentos morais de injustiça. 
Trata-se, pois, na esteira de Hegel, de uma perspectiva bem distinta daquela da "luta de todos contra todos" que orientou Maquiavel e Hobbes. A luta por reconhecimento expressa a necessidade do sujeito fazer-se reconhecido cada vez em novas dimensões de sua própria pessoa e implica um tipo de conflito que somente pode ser solucionado por meio da ampliação do reconhecimento para níveis superiores.

Nosso propósito, no presente texto, é partir das teses centrais da teoria do reconhecimento honnethiana, explicitar diferentes dimensões do conflito presentes nela e mostrar como é possível encontrar, em sua obra, um importante vínculo entre conflito e formação, de modo especial, em face aos conceitos de socialização e autorrealização.

\section{As teses centrais da teoria do reconhecimento honnethiana}

Para identificar o vínculo entre conflito e formação, faz-se necessário retomar, inicialmente, de modo sumário, as três teses centrais buscadas por Honneth na teoria do reconhecimento do jovem Hegel e confrontadas empiricamente com a psicologia social de Mead. A primeira delas é a de que a constituição da identidade subjetiva individual pressupõe o reconhecimento recíproco entre sujeitos. Ela é assim detalhada pelo autor: "só quando dois indivíduos se vêem confirmados em sua autonomia por seu respectivo defrontante, eles podem chegar de maneira complementária a uma compreensão de si mesmos como um Eu autonomamente agente e individuado" (HONNETH, 2003, p.119120). O autor concebe a ordem moral da sociedade burguesa-capitalista como uma estrutura institucionalizada de relações de reconhecimento e propõe-se a demonstrar que existe uma dependência caracteristicamente humana do reconhecimento intersubjetivo. Tal dependência configurase pela maneira própria como se institucionaliza a concessão mútua de reconhecimento numa determinada sociedade. Há, assim, uma espécie de condição intersubjetiva dos seres humanos e a capacidade humana que torna possível o reconhecimento - a autorrelação prática do sujeito - não é algo dado de uma vez por todas, mas desenvolvido mediante um processo capaz de ampliar-se intersubjetivamente na forma de um "reconhecimento social de componentes específicos da personalidade" (HONNETH, 2003a, 
p. 138). Essa primeira tese exprime a premissa fundamental de toda a sua teoria do reconhecimento, a saber, a de que a identidade pessoal possui uma estrutura fundamentalmente intersubjetiva. A tese retoma a fórmula fichteana de que o homem só se constitui como homem entre os homens (FISCHBACH, 1999, p. 52-66).

A segunda tese refere-se à existência de formas de reconhecimento recíproco - amor, direito e estima social - que se distinguem pelo grau de autonomia que o sujeito possui. Ela parte da premissa da intersubjetividade e afirma a existência de formas de reconhecimento que propiciam ao sujeito distintos graus de autonomia. Nas sociedades modernas, os sujeitos dependem dessas três formas de reconhecimento social para a formação de sua identidade. Tratam-se, pois, de padrões em virtude dos quais os indivíduos podem confirmar-se de modo recíproco e cada vez maior como pessoas autônomas e individuadas (HONNETH, 2003). Assim entendido, o reconhecimento afetivo possibilita ao indivíduo adquirir confiança em si mesmo, o reconhecimento jurídico confere-lhe o status de ser reconhecido como membro da sociedade protegido por determinados direitos e o reconhecimento social propicia-lhe aprender a compreender-se como sujeito que possui determinadas habilidades e talentos valiosos para a sociedade.

Por fim, a terceira tese indica haver a lógica de um processo de formação (Bildung) que corresponde à sequência das três formas de reconhecimento mencionadas e que se realiza através da luta moral, entendida como luta por reconhecimento. A motivação do conflito é o desrespeito ou o não reconhecimento de determinadas pretensões de autonomia do sujeito. Nessa tese, estão implicadas duas afirmações fortes. A primeira é a de que "faz parte da condição de um desenvolvimento bem sucedido do Eu uma sequência de formas de reconhecimento recíproco"; a segunda indica que a ausência de tal sequência "se dá a saber aos sujeitos pela experiência de um desrespeito, de sorte que eles se vêem levados a uma luta por reconhecimento" (HONNETH, 2003, p.122)

$\mathrm{O}$ conceito de reconhecimento situa-se no centro de um projeto teórico que tem como norte a ideia de que os seres humanos constituemse como humanos somente mediante processos intersubjetivos orientados pela busca de reconhecimento. Nesse sentido, a formação da identidade do indivíduo ocorre em face das etapas de interiorização das respostas 
de reconhecimento socialmente estandarizadas. Os indivíduos dependem de um contexto permeado por formas de interação social, regido por princípios normativos de reconhecimento mútuo e, quando as relações de reconhecimento são prejudicadas, surgem experiências de desrespeito ou humilhação com consequências lesivas para a formação de sua identidade. A questão central que orienta a ideia de reconhecimento dirá respeito, pois, ao significado de os indivíduos serem reconhecidos como pessoas de valor. Isso significa que os indivíduos só podem constituir-se como pessoas em razão de que, da perspectiva dos outros, aprendem a referir positivamente a si mesmos como seres aos quais competem certas propriedades e capacidades. Em outros termos, os indivíduos aprendem a ver-se a si mesmos de modo positivo na medida em que vão se convencendo das capacidades e necessidades específicas que os constituem como personalidades e isso ocorre por meio da "reação de apoio de seus parceiros de interação generalizados” (HONNETH, 2003a, p. 173).

Uma autorrelação positiva, mediante a qual o indivíduo pode referir a si próprio como sujeito, está associada ao desenvolvimento dessas propriedades e capacidades em diferentes expectativas e formas de reconhecimento. Emcadauma delas, oindivíduodesenvolveumdeterminado tipo de relação prática consigo próprio, adquirida de maneira intersubjetiva: a autoconfiança nas relações amorosas e de amizade; o autorrespeito nas relações jurídicas, em sua condição de membro responsável, parte de uma sociedade; a autoestima na comunidade de valores, em que é reconhecido por suas capacidades e contribuições à sociedade. Em diferentes graus, as experiências de desrespeito podem abalar tal autorrelação prática positiva da pessoa, de modo a privá-la do reconhecimento de determinadas pretensões de identidade. Tais experiências ferem a autorrelação prática de modo que, a cada uma das formas de reconhecimento apresentadas, corresponde uma forma de desrespeito que é, respectivamente: violação e maus-tratos, as quais afetam a integridade física e, em decorrência, a autoconfiança; privação de direitos e exclusão, que gera experiências de rebaixamento, afetando o autorrespeito moral; e degradação e ofensas, que suscita referência negativa ao valor social de indivíduos ou grupos, afetando a sua autoestima (HONNETH, 2003, p. 213s.). 
As experiências de desrespeito estão, pois, na base da luta por reconhecimento e indicam o papel central que o conflito assume nesse modelo de teoria crítica. Todavia, antes de tratarmos de modo específico do tema do conflito, faz-se necessário um esclarecimento afim de não deixar a impressão de que Honneth assumiria in totum a ideia hegeliana de conflito. Cabe ressaltar que a proposta de Honneth, embora profundamente vinculada a Hegel, distingue-se claramente deste em dois aspectos essenciais (HONNETH, 2003a, p. 144-146). O primeiro é que, embora Hegel (2003) procure indicar em sua Filosofia do direito, a existência de um tipo de conflito intrínseco em cada uma das três esferas de reconhecimento - família, sociedade civil e estado -, isso só serve para motivar a transição de um nível para o outro no âmbito das instituições constituintes do plano ético. O problema estaria em que, ao pretender dar conta de um fechamento sistemático e harmonioso da totalidade ética Hegel, apesar de todas as tensões internas à vida ética, não ousou ver a luta inserida de modo estrutural em cada uma das esferas de reconhecimento.

$\mathrm{O}$ segundo aspecto reside em que, além de negar os conflitos intrínsecos às três esferas de reconhecimento por ele identificadas, Hegel tratou também de equipará-las a complexos institucionais próprios de sua época, a saber, respectivamente: à família nuclear burguesa, à estrutura organizativa da sociedade burguesa e, por fim, ao estado moderno burguês (HONNETH, 2007a, p. 117). Em decorrência, abdicou da possibilidade de vincular sistematicamente à sua análise outras expressões institucionais dos princípios do reconhecimento, como é o caso da amizade no que se refere à relação ética do amor. Honneth defende a posição de que somente em casos raros os complexos institucionais representam um princípio único de reconhecimento, sendo que isso se deve ao fato de, em geral, eles se ancorarem em distintos princípios de reconhecimento, uma vez que as esferas do amor, do direito e da estima social colocam-se acima do nível concreto das instituições sociais ou jurídicas. Exemplo disso é o papel que o princípio do direito desempenha em relação às demais esferas de reconhecimento em razão de possuir um potencial intrínseco para intervir corretivamente nelas a fim de garantir condições mínimas da identidade do sujeito quando as condições da autonomia individual não estiverem suficientemente protegidas (HONNETH, 2003a). 


\section{Dimensões do conceito honnethiano de conflito}

Experiências de desrespeito estão na base de conflitos que traduzem uma quebra de expectativas normativas presentes na base da sociedade e que, por conseguinte, podem converter-se em luta por reconhecimento. Esta última é apresentada por Honneth como a gramática moral dos conflitos sociais e o conflito é entendido como base da interação social.

A propósito, vale salientar que é justamente nesse aspecto que o modelo de teoria crítica de Honneth procura distinguir-se do modelo habermasiano. Embora não seja nosso objetivo aprofundar, esse aspecto cabe, no entanto, uma breve consideração a respeito. Ao invés de enveredar o caminho de uma teoria da ação comunicativa baseada numa pragmática formal da linguagem, Honneth opta por um modelo de teoria crítica que toma como âncora uma gramática moral dos conflitos sociais. A ênfase não será atribuída ao consenso, compreendido como telos da interação, mas ao conflito. Na teoria da sociedade de Habermas, a dimensão do conflito teria ficado em segundo plano, de modo que Honneth critica a intersubjetividade orientada para o entendimento e volta-se para a dimensão das experiências de desrespeito. A teoria de Habermas padeceria de um déficit sociológico, pois lhe faltaria tematizar os fundamentos normativos da crítica a partir da dinâmica social dos inseridos nela. Tais fundamentos poderiam ser encontrados nas experiências de injustiça e humilhação e nos conflitos que resultam delas (WERLE; MELO, 2008). A juízo de Honneth (2007), o problema é que, na perspectiva de Habermas, o processo emancipatório dimensão em que este último baseia socialmente a perspectiva normativa da teoria crítica - não se apresenta nas experiências morais dos sujeitos envolvidos. Aquilo que esses sujeitos experimentam como um prejuízo de suas expectativas morais não pode ser considerado apenas como uma restrição de regras de linguagem por eles dominadas intuitivamente, como em Habermas, mas como uma restrição de exigências de identidade adquiridas por meio da socialização.

Dessa crítica, decorre a posição de que o próprio modelo do social de Habermas, centrado nas relações de comunicação com base numa teoria da linguagem, teria de ser deslocado na direção de uma teoria do conflito, ou seja, o modelo do entendimento comunicativo deveria dar lugar ao de 
luta por reconhecimento, considerando-se que esse é calcado nas condições prévias intersubjetivas que proporcionam o desenvolvimento da identidade humana de um modo geral. Tais condições residem nas formas de comunicação social em que o indivíduo cresce, desenvolve a sua identidade e aprende a conceber-se como membro de uma sociedade (HONNETH, 2007). Para Honneth, são as relações de reconhecimento que formam a identidade dos indivíduos e grupos humanos e o conflito está na base de tal formação. Por conseguinte, ao invés de se deter na tensão entre sistema e mundo da vida, como fizera Habermas, a teoria crítica deveria voltar-se para as causas da violação das condições de reconhecimento ${ }^{1}$. Isso é possível em razão de Honneth situar o seu modelo de teoria crítica no âmbito de uma filosofia social que tem como escopo a tematização de patologias sociais ${ }^{2}$.

O tema do conflito em Honneth é situado a partir de sua teoria crítica configurada como filosofia social e está vinculado estreitamente a já mencionada violação das condições de reconhecimento que incide sobre a identidade do sujeito e a sua capacidade de autorrealização. É justamente esse risco de violação ou de lesão das condições intersubjetivas pressupostas na forma da autoconfiança, do autorrespeito e da autoestima que impulsiona a busca por reconhecimento. Portanto, trata-se de mostrar que a ideia de formação mediante o reconhecimento tem como base e mola propulsora o conceito de conflito, e procuraremos fazê-lo, aqui, a partir de cinco considerações.

a) Cada uma das esferas de relações de reconhecimento distinguese por um conflito interno referente à aplicação legítima de seu princípio de reconhecimento, a saber, respectivamente: amor, igualdade e êxito. À luz de cada um desses princípios, o sujeito

\footnotetext{
Sobre as categorias de sistema e mundo da vida cf. HABERMAS, 1987, p.171s.

2 Honneth se insere na tradição que remonta aos autores tanto do círculo interno quanto externo do Instituto de Pesquisa Social, bem como a Habermas, que interpretam a situação social própria às sociedades capitalistas contemporâneas como um "estado de negatividade social", portador de patologias sociais. Essa negatividade deveria ser avaliada no sentido de algo que lesa as condições de uma vida boa ou bem sucedida, de modo que as patologias sociais afetam as condições para a autorrealização dos indivíduos. Para Honneth (2006), assim como para os diferentes representantes da teoria crítica, é justamente a falta de racionalidade social o fator que causa as patologias da sociedade capitalista.
} 
pode expressar, quando for o caso, experiências concretas de desrespeito e, por essa via, colocar as bases para a ampliação do reconhecimento em cada uma de suas três esferas (Honneth, 2003a, p. 144-145). Na esfera das relações afetivas, o conflito interno visa a colocar necessidades recém-desenvolvidas ou que ainda não foram levadas em conta. Apela-se, nesse caso, ao amor mutuamente testemunhado entre mãe e filho com a finalidade de obter um tipo de atenção diferente ou mais amplo do que até então tivera3. Na esfera do direito, o conflito está baseado na ideia de igualdade e visa a mostrar que os grupos antes excluídos merecem ser legalmente reconhecidos. Na esfera social, o conflito leva os indivíduos ou os grupos a promoverem atividades e capacidades que até então eram descuidadas ou subvalorizadas. A finalidade do conflito, aqui, é exigir tanto uma estima social maior quanto uma justa redistribuição de recursos materiais.

b) Conformejá referimos anteriormente, o tipo de conflito que interessa a Honneth é aquele originado por experiências de desrespeito que afetam a identidade dos sujeitos, o reconhecimento denegado. Em razão de o conflito ser entendido como expressão própria de experiências morais que emanam da lesão de expectativas de reconhecimento profundamente arraigadas, a pretensão de Honneth é formular uma teoria social de teor normativo, vinculando um conceito de luta que parta de sentimentos morais de injustiça. $\mathrm{O}$ seu foco são as experiências morais associadas aos processos de negação do reconhecimento para indicar como o conflito pode traduzir-se na forma de luta por reconhecimento, a qual vincula uma força moral capaz de impulsionar o sujeito à ação. Sua concepção de conflito não deve ser concebida, no entanto, apenas mediante um quadro explicativo acerca do surgimento de lutas sociais, mas, principalmente, a partir do caráter normativo de uma luta moral. Esse sentido moral da luta está associado à pretensão mútua dos

3 Honneth corrige, em Redistribution or recognition? (2003a, p. 144), algo que defendia em 1992, em Luta por reconhecimento (2003, p. 276), a saber, que o amor não admitia potencial para o desenvolvimento normativo. 
indivíduos de que a sua identidade seja reconhecida pelos outros. Essa pretensão é inerente à vida social, concebida como tensão normativa que leva a conflitos morais entre sujeitos que dependem socialmente uns dos outros. A luta desencadeada entre os sujeitos é um acontecimento moral e é constituída com relação à meta do reconhecimento intersubjetivo. A luta por reconhecimento é o meio de ação social pelo qual a relação entre os sujeitos pode adquirir gradativamente uma forma moral mais ambiciosa e, desse modo, levar a níveis mais desenvolvidos da relação social, viabilizando um crescimento tanto da socialização quanto da individuação.

c) Como a luta social é interpretada a partir de experiências morais, não fica pré-determinado por quais meios práticos as experiências de desrespeito podem ser superadas; se, por exemplo, por força material ou simbólica. $\mathrm{O}$ ponto central reside em como articular as expectativas privadas dos indivíduos em relação ao desrespeito sofrido e às finalidades impessoais do movimento social. Entre ambas, precisa haver uma ponte semântica que deve permitir a construção de uma identidade coletiva. Por conseguinte, somente quando o sentimento de desrespeito converter-se em base motivacional de resistência coletiva, articulado num quadro de interpretação intersubjetivo, é que o conflito pode transformarse em mola propulsora para a luta por reconhecimento. Quando convertidos em luta por reconhecimento, conflitos oriundos de experiências de desrespeito vinculam uma força moral capaz de promover desenvolvimentos e progressos na vida social e o reconhecimento do sujeito como pessoa de valor (Honneth, 2003).

d) As reações emocionais negativas assumem uma importância fundamental para impulsionar a luta por reconhecimento. As experiências de desrespeito vinculam determinadas reações psíquicas negativas que podem constituir a base motivacional afetiva para a luta por reconhecimento. Portanto, se, por um lado, as experiências de desrespeito como a humilhação e a exclusão ameaçam a própria integridade ou a identidade dos indivíduos, por outro, podem converter-se no impulso motivacional da luta 
por reconhecimento. A crítica de Honneth a Hegel e a Mead, a esse respeito, reside no fato de que faltaria neles justamente o elo psíquico que torna possível passar do desrespeito à ação. Tal elo seria o fator que desempenharia o papel de informar cognitivamente à pessoa que experiencia o desrespeito sobre a sua situação social (Honneth, 2003). Essa função de passar do sofrimento à ação pode ser desempenhada por reações emocionais negativas e é, principalmente, sentimentos como a vergonha e o desprezo que dão a base para um sujeito reconhecer a negação injustificada do reconhecimento social. Daí, a tese de que para chegar a uma autorrelação bem sucedida o indivíduo depende do reconhecimento intersubjetivo de suas capacidades e realizações. Se, ao contrário, essa forma de assentimento social não ocorrer em alguma das etapas de seu desenvolvimento, acontecerá de se abrir na personalidade uma espécie de uma lacuna psíquica, entrando reações emocionais negativas nela, como a vergonha e a ira. A abertura de tal lacuna é possível em razão de que a experiência de desrespeito vem sempre acompanhada de sentimentos afetivos, os quais podem indicar ao indivíduo que "determinadas formas de reconhecimento lhe são socialmente denegadas" (Honneth, 2003, p. 220). Por conseguinte, é quando as expectativas de reconhecimento profundamente arraigadas são desapontadas que se torna possível desencadear um tipo de experiência moral que se expressa por meio do sentimento de desrespeito.

e) A tese de que o estabelecimento de uma relação positiva consigo mesmo associa-se à capacidade de o sujeito ser reconhecido como pessoa de valor é tematizada por Honneth, recorrendo à concepção de sentimentos de Dewey. Para Honneth, os sentimentos representam reações afetivas que decorrem do êxito ou não de nossas ações e intenções práticas. Esse ponto de partida auxilia-o a encontrar uma via para distinguir os tipos de perturbações que incidem sobre a ação humana e que são avaliadas pelas expectativas que orientam a própria ação. $\mathrm{O}$ que leva a conflitos morais na esfera do mundo da vida é a infração de normas pressupostas como 
válidas que se traduzem em sentimentos morais de injustiça. As diferenças entre as reações emotivas são medidas de acordo com a violação de normas que refreiam a ação. Este refreamento pode advir tanto do próprio sujeito quanto de quem compartilha com ele a interação. No primeiro caso, vivencia-se o contrachoque de suas ações com sentimentos de culpa; no segundo, com sentimentos de indignação. De acordo com Honneth (2003), o ponto central vislumbrado por Dewey, nessas experiências de vivência afetiva de ações rechaçadas, reside na tomada de consciência do elemento cognitivo das próprias expectativas, qual seja, o saber moral que conduziu à ação que foi refreada. Honneth entende que, nas reações emocionais decorrentes da vergonha, as experiências de desrespeito podem adquirir o impulso motivacional necessário para uma luta por reconhecimento. Isso ocorre em razão de que a tensão afetiva gerada ao indivíduo na forma de vergonha e humilhação só pode ser dissolvida na possibilidade efetiva da ação. Dentre os sentimentos morais, Honneth destaca o da vergonha, por possuir o caráter mais aberto e por traduzir-se como uma espécie de rebaixamento do próprio valor do sujeito. Isso ocorre por tratar-se de um sentimento vivenciado "somente na presença de parceiros de interação, reais ou imaginados, aos quais incumbe de certa maneira o papel de testemunha da lesão dos ideais de ego" (HONNETH, 2003, p. 223) $)^{4}$.

\section{Socialização e autorrealização: algumas perspectivas extraídas da relação existente entre conflito e formação em Honneth}

Verificamos anteriormente que, como impulso para a luta por reconhecimento, o conflito permite a formação da identidade individual. Tomando essa ideia central como referência, pretendemos explorar, agora, os conceitos de socialização e autorrealização, os quais ajudam a explicitar

\footnotetext{
4 A vergonha pode ser causada pela própria pessoa ou por outrem. No primeiro caso, "o sujeito se vivencia como de menor valor"; no segundo caso, "o sujeito é oprimido por um sentimento de falta do próprio valor" (2003, p. 223). A esse respeito, ver também La Taille, 2002, p.163s. e Tugendhat, 1993, p.60s.
} 
aspectos importantes do vínculo existente entre conflito e formação em Honneth.

Atualmente, é variado o espectro das compreensões sobre a socialização, mas Honneth, embora não seja um teórico desse campo no sentido estrito do termo, pode ser situado a partir da tradição que compreende socialização como interação ${ }^{5}$. Sua contribuição a esse respeito situa-se ao destacar o papel das interações voltadas à busca por reconhecimento como resultantes de processos conflitivos motivados pela quebra de expectativas normativas socialmente arraigadas. Cabe, pois, levar em conta, aqui, o conceito de conflito associado a processos de socialização, mas mantendo o seu sentido de fundo, ou seja, a força moral contida em experiências de desrespeito. É possível compreender a formação da identidade humana como um fenômeno que, em razão de sua natureza prática, dificilmente pode ser pensada sem a ideia de conflito, o qual é intrínseco à formação tanto da identidade dos sujeitos singulares quanto dos processos de constituição da intersubjetividade. O próprio Mead (1967) já explicitara isso ao mostrar que o sujeito, muitas vezes, sente o afluxo de normas intersubjetivas oriundas do meio social, tendo que colocar em dúvida seu próprio Me.

Como registra Honneth, "o 'Me' incorpora, em defesa da respectiva coletividade, as normas convencionais que o sujeito procura constantemente ampliar por si mesmo, a fim de poder conferir expressão social à impulsividade e criatividade do seu 'Eu'” (2003, p. 141). O atrito entre o I e o Me, entre a identidade pessoal e a identidade social, representaria o conflito fundamental para explicar o desenvolvimento moral tanto dos indivíduos quanto da sociedade ${ }^{6}$.

A se compreender os processos de interação como processos de socialização na linha da tradição que remonta a Simmel $(1981 ; 1999)$ e, pois, como dinâmicos e abertos à contingência, pode-se, com alguma facilidade, encontrar aí também o conflito como uma de suas dimensões

5 Um bom panorama sobre essa tradição pode ser encontrado em Grigorowitschs (2010).

6 A denominação de identidade pessoal (personliche Identität) para o I e de identidade social (soziale Identität) para o Me é de Habermas, baseando-se em Erving Goffman (HABERMAS, 1973, p. 131). 
constitutivas. O que há em comum entre autores como Simmel, Mead e Habermas é a ideia de que os processos de socialização estão diretamente vinculados às interações humanas. É mediante tais processos que a identidade dos indivíduos configura-se, o que não ocorre de maneira linear.

A contribuição importante de Honneth a essa tradição é a introdução do tema do conflito como central para a compreensão das interações sociais e da formação da identidade humana, bem como para o desencadeamento de ações emancipatórias. Isso é levado adiante, como vimos, pela ideia de que, quando o indivíduo vivencia experiências de negação de reconhecimento em qualquer um dos três padrões sugeridos, são afetados aspectos constitutivos de sua própria identidade, o que pode gerar consequências drásticas para o êxito dos processos de socialização e para os processos educativos em sentido mais específico.

A teoria de Honneth coloca, no seu centro, a tensão conflitoreconhecimento e se retomar-se, aqui, a premissa que perpassa tal tensão, a saber, a ideia de que a identidade do sujeito possui uma estrutura fundamentalmente intersubjetiva, há que se levar em consideração que tal estrutura advém de processos de socialização e que, nas experiências de desrespeito, tais processos são prejudicados. Ambientes educativos são perpassados pelas interações que permeiam o conjunto do tecido social, ficando, pois, vulneráveis às experiências que, daí, emanam inclusive as de desrespeito. Instituições educativas deveriam considerar as formas de desrespeito advindas do âmbito social, estando atentas para atender possíveis violações de expectativas normativas, ancoradas em seu contexto interno de interação. Vale ressaltar que, para Honneth, o conflito decorre da violação de expectativas de reconhecimento enraizadas nas relações de reconhecimento. São essas expectativas subjacentes aos processos de formação da identidade que permitem ao sujeito compreender-se como autônomo e individualizado. Portanto, a violação de expectativas de reconhecimento enraizadas nas relações sociais pode implicar experiências morais de desrespeito e, nesse caso, a violação da autonomia e da identidade do sujeito.

Instituições educativas, concebidas como instâncias socializadoras que são, ficariam ameaçadas em seu papel formativo quando afetadas as condições para o estabelecimento de uma relação positiva dos sujeitos para si próprios e, pois, seu acesso à autonomia. Como destaca Voirol: 
a expectativa de reconhecimento não preenchida supõe uma perturbação do processo intersubjetivo da construção de si e faz com que os atores, ao se verem como vítimas da negação do reconhecimento no processo intersubjetivo de socialização, se revelem pouco dispostos à autonomia do juízo e à afirmação de uma dinâmica pública de argumentação (2008, p. 51).

Honneth frisa que "a socialização dos seres humanos só pode ser bem sucedida sob condições de liberdade cooperativa" (2006a, p. 110). Em outros termos, a autorrealização individual só é possível quando combinada com a autorrealização de todos os demais membros da sociedade por meio de princípios ou fins aceitos por todos. Nesse sentido, observa ainda, na esteira de Hegel e de Adorno, que "somente pode haver formas bem sucedidas de socialização onde forem estabelecidos modos de ação em comum que possam valer como metas racionais de autorrealização desde a perspectiva de todos os sujeitos individuais" (HONNETH, 2006a, p. 111).

Honneth vale-se da ideia de que as expectativas normativas dos sujeitos estão orientadas para o "reconhecimento social de suas capacidades por outros diversos outros generalizados" (2006a, p. 173). Portanto, essa posição implica uma concepção de socialização moral do sujeito em que a formação da identidade individual acontece através das etapas de interiorização de respostas de reconhecimento "socialmente estandarizadas". Isso significa que "os indivíduos aprendem a veremse a si mesmos como membros plenos e especiais da comunidade ao ir gradualmente se assegurando das capacidades e necessidades específicas que os constituem como personalidades mediante a reação de apoio de seus parceiros generalizados de interação" (2006a, p. 173). Por essa razão, os sujeitos dependem de um contexto de formas de interação social orientado por princípios normativos de reconhecimento mútuo. Quando essas relações de reconhecimento deixam de existir, elas cedem lugar a experiências de falta de respeito ou humilhação que deixam consequências lesivas para a formação da identidade do indivíduo.

Honneth, aqui, ampara-se num pressuposto ético fundamental de sua teoria do reconhecimento, qual seja: "dos membros de uma sociedade deve poder dizer-se que eles poderão levar em comum uma vida bem 
sucedida e não deformada somente se todos eles se orientarem em função de princípios ou instituições que eles mesmos possam compreender como metas racionais de sua auto-realização" (2006a, p. 107). Nesse sentido, uma pedagogia do reconhecimento exigiria ir além das premissas individualistas do liberalismo, pois demandaria levar em conta o princípio da liberdade cooperativa de modo a entender as relações pedagógicas como normativamente orientadas por tal princípio. A teoria do reconhecimento distingue-se do liberalismo justamente por um perfeccionismo ético de caráter muito peculiar, a saber, que a meta normativa da sociedade deve consistir em tornar a autorrealização mutuamente possível. Todavia, essa meta deve ser concebida como processo de formação do ser humano (HONNETH, 2006a).

A formação do eu prático vincula-se diretamente à possibilidade do estabelecimento de relações de reconhecimento recíproco entre sujeitos, uma vez que é somente quando os indivíduos vêem-se confirmados em sua autonomia pelos demais que podem chegar a uma compreensão de si mesmos na condição de "um Eu autonomamente agente e individuado" (HONNETH, 2003, p. 120). Baseado nos estudos de Mead, Honneth vincula a ideia de que um sujeito só pode adquirir a consciência de si mesmo na medida em que aprender a perceber a sua própria ação simbolicamente representada a partir da perspectiva de uma segunda pessoa. Ao princípio do reconhecimento é claramente vinculado um papel formativo, visto que a busca de autorrealização é concebida como resultado de um processo de autoconstituição intersubjetiva do ser humano. Na base de tal processo, está o conflito como modo de impulsionar o sujeito à formação prática de sua identidade. Conforme já destacamos ${ }^{7}$, essa pretensão de reconhecimento, que permite constituir a identidade humana, é inerente à vida social e traduzse na forma de uma tensão entre sujeitos que dependem socialmente uns dos outros. Esse processo conflitivo de formação demanda a experiência do reconhecimento que só será possível se o sujeito constituir uma relação positiva consigo mesmo mediante a relação com os outros. Afirma Honneth, "os indivíduos se constituem como pessoas unicamente porque, da perspectiva dos outros que assentem ou encorajam, aprendem a se

\footnotetext{
7 Conforme acima, item 2, letra (b).
} 
referir a si mesmos como seres a quem cabem determinadas propriedades e capacidades" (HONNETH, 2003, p. 272). Sem o desenvolvimento delas não seria possível haver êxito na autorrealização, a qual depende da realização espontânea de metas de vida escolhidas de modo autônomo.

Por conseguinte, para Honneth, assim como para Hegel, uma formação bem sucedida da própria identidade demanda determinadas condições para a autorrealização do indivíduo e esta só pode ser exitosa se for unida com a autorrealização de todos os demais sujeitos em face de princípios ou fins racionais capazes de serem aceitos desde a perspectiva de todos e de cada um. O desvio dessa meta é gerador de patologias sociais porque implica a perda da autorrealização em sentido intersubjetivo ${ }^{8}$. A concepção de vida boa, a qual está associada à ideia de autorrealização do sujeito, deve ser entendida numa perspectiva pós-tradicional e no contexto de sociedades complexas e pluralistas. Essa noção de vida boa não pode, todavia, ser identificada tout court com convicções de valor substanciais vinculadas à multiplicidade de mundos da vida particulares, ou seja, com o ethos de comunidades singulares. Por outro lado, ela deve ser tão repleta de conteúdo de modo a ser possível saber mais sobre as condições de autorrealização do que é possibilitado pela autonomia individual kantiana. É justamente por isso que, de acordo com Honneth, a teoria do reconhecimento situar-se-ia no ponto intermediário entre a teoria moral kantiana e as éticas comunitaristas. Em outras palavras, ela precisa ser pensada para além de Kant pela necessidade de contemplar não apenas a autonomia moral do ser humano, mas as suas condições de autorrealização como um todo; deve ser situada para além das éticas comunitaristas em razão de que o conceito de vida boa não se limita a convicções axiológicas substanciais.

A teoria do reconhecimento deve vincular um conceito de vida boa que oriente os objetivos da autorrealização humana e, ao mesmo tempo, necessita guiar-se por normas universais orientadoras da ação. Ela deve buscar determinações formais da vida boa, mas sem perder de vista os contextos e as formas de vida particulares - o denominado

8 A esse respeito vide nota 5, acima. A abordagem de Honneth aqui se desvia de Kant - abandonando uma concepção estreita da moral - para se aproximar de Hegel uma vez que o seu foco não é contemplar apenas o sentido da autonomia moral, mas, sobretudo, as "condições de auto-realização como um todo" (2003, p. 271). 
universalismo contextualista (HONNETH, 2009). Em decorrência, as condições intersubjetivas para que a autorrealização e a integridade pessoal sejam asseguradas dependem do grau de desenvolvimento das relações de reconhecimento historicamente constituídas. A abordagem de Honneth, nesse sentido, vai além de Kant porque o seu objetivo não é tratar somente da autonomia moral, mas também das condições de autorrealização do ser humano como um todo. Portanto, tal conceito pretende ampliar a moralidade "no sentido de integrar num mesmo quadro tanto a universalidade do reconhecimento jurídico-moral da autonomia individual quanto a particularidade do reconhecimento ético da autorealização pessoal"' (WERLE; MELO, 2007, p. 16).

A autonomia do sujeito, entendida como liberdade de autorrealização, depende de determinados pressupostos, haja vista que ela só pode ser adquirida com seus parceiros de interação. Por essa razão, pensa Honneth, os diferentes padrões de reconhecimento representam condições intersubjetivas e são apresentados como necessários para "descrever as estruturas universais de uma vida bem sucedida" (2003, p. 273). Os três padrões de reconhecimento - amor, direito e solidariedade - são considerados como condições para a autorrealização e são suficientemente formais para não incorporarem ideais de vida específicos. Por outro lado, são ricos em termos de conteúdo a ponto de irem além, no que se refere às estruturas universais de uma vida bem sucedida, da referência apenas à autodeterminação individual. Uma teoria do reconhecimento que vincule uma concepção pós-metafísica de vida boa deve valer-se de padrões suficientemente formais para deixar, em aberto aos indivíduos, distintas opções de autorrealização e, pois, de formação de suas identidades.

Para concluir, a nosso ver, a teoria do reconhecimento de Honneth contém um rico potencial teórico a ser explorado em relação à esfera formativa. Nosso esforço limitou-se a analisar o eixo conflito-formação, articulado às noções de socialização e autorrealização, sem entrar ainda no detalhamento de seus possíveis limites. Se esse esforço for válido, poderá contribuir com a tarefa mais ampla de vislumbrar novas perspectivas na direção de uma teoria crítica da educação pensada normativamente como formação mediante o reconhecimento e orientada a partir de um prisma pós-metafísico. Se as experiências de desrespeito constituem-se como 
a principal patologia das sociedades contemporâneas, como defende Honneth, então uma formação dos sujeitos orientada pelo princípio do reconhecimento recíproco ganharia uma relevância ímpar para pensarse em possibilidades educativas em perspectiva emancipatória no atual cenário de sociedades complexas e pluralistas.

\section{Referências}

FISCHBACH, F. Fichte et Hegel: la reconnaissance. Paris: P.U.F., 1999. GRIGOROWITSCHS, T. Entre a sociologia clássica e a sociologia da infância: reflexões sobre o conceito de "socialização". Disponível em: $<$ www.aps.pt/vicongresso/pdfs/33.pdf>. Acesso em: 04 Abr. 2010.

HABERMAS, J. Stichworte zu einer Theorie der Sozialisation. Kultur und Kritik. Frankfurt am Main: Suhrkamp, 1973.

. Theorie des Kommunikativen Handelns. Frankfurt am Main: Suhrkamp, 1987 (Bd.2).

HEGEL, G.W.F. Des manières de traiter scientifiquement du droit naturel. Paris: Vrin, 1972.

. Système de la vie éthique. Paris: Payot, 1992.

. Principes de la philosophie du droit. 2.ed. Paris: PUF, 2003.

HONNETH, A. Luta por reconhecimento: a gramática moral dos conflitos sociais. São Paulo: Editora 34, 2003.

. Redistribution as recognition: a response to Nancy Frazer (p. 110197); The point of recognition: a rejoinder to the rejoinder (p.237-267). In: FRAZER, N.; HONNETH, A. Redistribution or recognition? A politicalphilosophical exchange. London: Verso, 2003a.

. La societé du mépris. Paris: La découverte, 2006.

- Une pathologie sociale de la raison. Sur 1'héritage intellectuel de la théorie critique. In: . La societé du mépris. Paris: La découverte, 2006a (p. 101-130).

. The social dynamics of disrespect: Situating critical theory today (p. 63-79) In: . Disrespect: the normative foundations of critical theory. Cambridge: Polity Press, 2007. 
- Reconnaissance et reproduction sociale. In: PAYOT, J.P.; BATTEGAY, A. (Ed.). La reconnassaince à l'épreuve: explorations sócio-anthropologiques. Villeneuve d'ascq: Presses Universitaires du Septentrion, 2008.

. Desarrollo moral y luta social. Enseñanzas de filosofia social de la obra temprana de Hegel. In: . Critica del agravio moral: Patologias de la sociedad contemporánea. Buenos Aires: Fondo de cultura Económica, 2009.

LA TAILLE, Y de. Vergonha, a ferida moral. 2. ed. Petrópolis: Vozes, 2002.

MEAD, G.H. Mind, self and society: from the Standpoint of a Social Behaviorist. Chicago and London: The University of Chicago Press, 1967. SIMMEL, G. Questions fondamentales de la sociologie. In: Sociologie et Épistémologie. Paris: PUF, 1981.

. SIMMEL, G. Sociologie. Études sur les formes de la socialization. Paris: PUF, 1999.

TUGENDHAT, E. Lições de ética. Petrópolis: Vozes, 1997.

WERLE, D.L.; MELO, R.S. Reconhecimento e justiça na teoria crítica da sociedade em Axel Honneth. In: NOBRE, M. (Org.). Curso livre de teoria crítica. Campinas: Papirus, 2008.

VOIROL, O. A esfera pública e as lutas por reconhecimento: de Habermas a Honneth. Cadernos de filosofia alemã, São Paulo, n. 11, p. 33-56, Jan./ Jun, 2008. 